\title{
Effect of Injection of Hydrocortisone into Nerves Thickened by Leprosy
}

\author{
W. H. JENNINGS, \\ Physiotherapist, Kondhwa Leprosy Hospital, Poona, India \\ (By courtesy of the Honorary Surgeons and Honorary Superintendent, Kondhwa Leprosy Hospital).
}

Perineural infiltration of hydrocortisone was carricd out on 12 patients with nerves thickened due to leprosy, at the Kondhwa I.cprosy Hospital, and the drug was found very efficacious in the patients treated carly. 'The patients treated were of all the three main types of leprosy.

\section{TECHNIQUE}

Hydrocortisone was injected round the lesioned nerve; $50 \mathrm{mg}$. twice a month (once in two weeks) in some cases, and in the other cases $25 \mathrm{mg}$. hydrocortisone diluted with 3 c.c. distilled water once a week. No hyaluronidase was used with hydrocortisone. Standard physiotherapy of electrical muscle stimulation, voluntary exercises of the involved muscles and splinting of the limb was administered to cases of complete paralysis.

Results: In the I 2 cases of cortisone treatment observed, 3 among these cases, one a pure lepromatous and the other two pure tuberculoids, had lesions on the ulnar nerve of more than a year in duration with paralysis of the intrinsic muscles supplied by the ulnar nerve to the degree of complete reaction of denervation. They did not respond to hydrocortisone treatment, $50 \mathrm{mg}$. given twice at the interval between each injection mentioned above. The remaining nine cases benefited from the drug. Photographs indicate the recovery from ulnar palsy of two patients among the successful nine, MR. K. T. N. and Mr. C. R. These two cases were of mixed leprosy. K.T.N. had severe neuromata of the ulnar nerve with anaesthesia in the region of the nerve supply and intrinsic muscle paralysis to the extent of partial reaction of denervation. He was first given hydrocortisone treatment 2 weeks after the signs of paralysis and anaesthesia, $25 \mathrm{mg}$. hydrocortisone diluted with 3 c.c. distilled water once a week. After the third injection signs of recovery from paralysis were noted. Hydrocortisone was discontinued but physiotherapy carried on. Two months after the first injection of cortisone he had totally recovered from paralysis and a partial recovery from anaesthesia was noted. A complete regression of the ncuromata was noted within a month of starting treatment. R.c. had no neuromata but had an enlarged ulnar nerve. He was given treatment six months after the development of ulnar anaesthesia and intrinsic muscle paralysis, the degree of paralysis being partial reaction of denervation of the muscles. He had one injection of $50 \mathrm{mg}$. hydrocortisone round the affected area of the nerve and physiotherapy was begun, so that two weeks after the injection the nerve appeared normal on palpation, and six weeks after this almost total recovery from paralysis was 

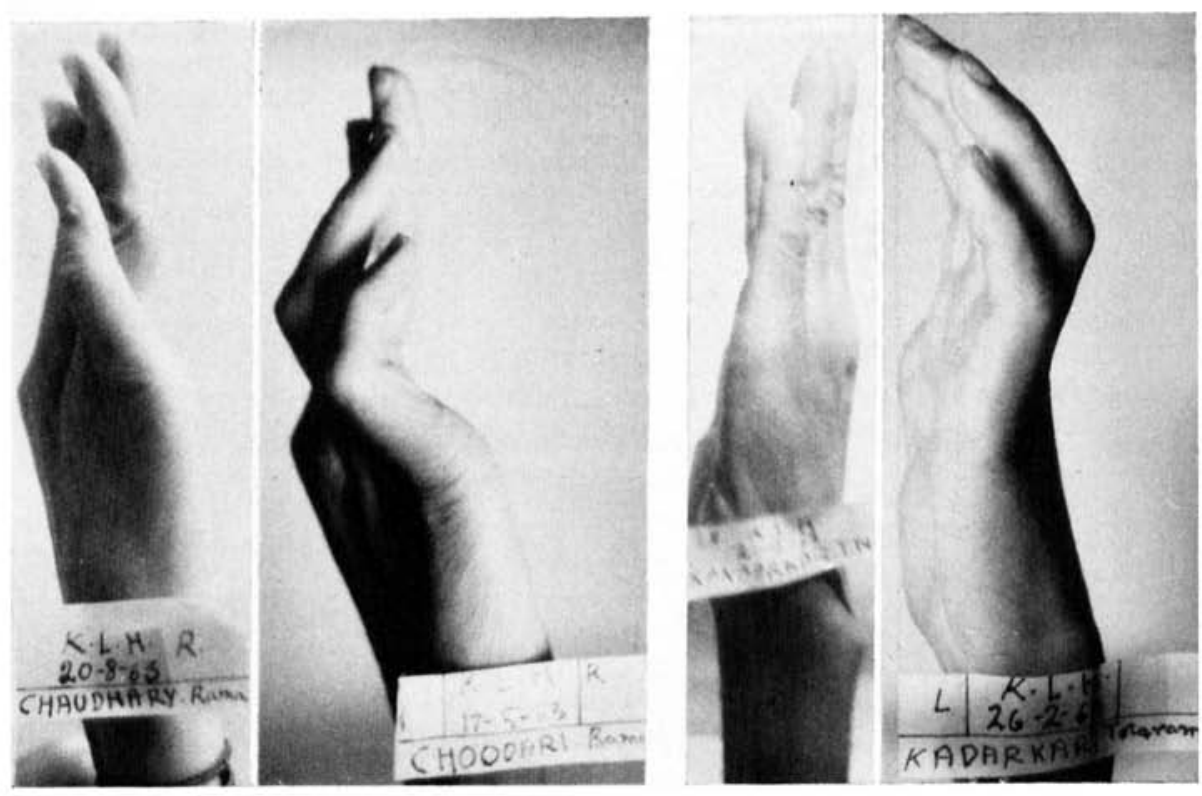

observed. There has not yet been sensory recovery in this case, though more than seven months have elapsed since the date of the injection.

Among the remaining seven cases, three patients of mixed leprosy and two of lepromatous leprosy had severe neuromata of the ulnar nerve, two among the mixed cases having very mild paralysis and anaesthesia. Each of these patients was put on cortisone treatment within two weeks of the appearance of signs of nerve involvement, by $50 \mathrm{mg}$. hydrocortisone given twice, round the site of the lesion. No physiotherapy of any nature was given to these five patients. Within two months of this treatment these five patients had normal nerves and the two had recovered from paralysis and anaesthesia. A tuberculoid case, among the remaining two, was given cortisone for bilateral foot drop, treatment being started within a month of the signs of lateral popliteal paralysis and the dosage being $25 \mathrm{mg}$. hydrocortisone injected round the affected area of each lateral popliteal nerve. Recovery was noted from paralysis within two weeks of the first injection and at this time he went home on leave for an emergency and did not return to complete his treatment. The last remaining case, of mixed leprosy, had a very enlarged and painful ulnar nerve with anaesthesia in the area of the nerve supply and partial atrophy of the hypothenar muscles. Cortisone and physiotherapy were begun a month after the signs of paralysis, dosage of the drug being $25 \mathrm{mg}$. hydrocortisone diluted with 3 c.c. distilled water once in a week. After four injections pain and swelling of the nerve subsided and though no recovery from paralysis or anaesthesia has been observed even after six months of the treatment there has also been no progress of the paralysis. 
COM M E N T S

In July i 959 there was an article in the Leprosy Reviere by w. H. JOPLING about the success of hydrocortisone treatment in a lepromatous case of foot-drop. 'This article is confirmatory of the facts mentioned by DR. JOPLING and any other persons who might have advocated the use of hydrocortisone in arresting or curing neural deformities due to leprosy.

S U M M A R Y

Hydrocortisone appears highly efficacious in preventing or curing neural deformities arising in connection with leprosy, the type of leprosy of the patient being immaterial provided treatment is started early.

THANKS:

In this work I was guided by DR. J. M. MFITA, Honorary Plastic Surgeon, Kondhwa I.eprosy lospital, and I wish to thank him for his kind help which has made this article possible.


for allowing me to publish this article. 